\title{
O desenho e o corpo como meio de expressão do desejo'
}

\author{
Andréia Cristina Dulianel²
}

\begin{abstract}
Resumo:
A partir do entrecruzamento entre a produção artística e a abordagem teórica, pretendo apresentar algumas reflexões presentes na minha pesquisa de doutorado em poéticas visuais, essencialmente, no que diz respeito a dois eixos explorados no processo de criação em desenho: a materialidade e a efemeridade. Além de questões referentes às intenções artísticas e às descrições do processo, pretendo evidenciar as técnicas de velamento, apagamento e sobreposição dos elementos da linguagem visual, na construção e desconstrução da imagem.
\end{abstract}

Palavras-chave: desenho; materialidade; efemeridade; expressão.

\section{Abstract:}

Taking into consideration the intersection between the artistic production and the theoretical approach, I intend to present some ideas from my PhD research in visual poetics, especially about two topics which were explored in the process of creation of the drawing: materiality and ephemerality. In addition to the questions related to the artistic intentions and process, I intend to approach the techniques of veiling, erasing, and overlapping the elements of the visual language, in the construction and deconstruction of the image.

Keywords: drawing; materiality; ephemerality; expression.
O presente texto foi construído a partir da pesquisa de doutorado, ainda em andamento, na linha de Poéticas Visuais e Processos de criação (PVPC) pelo Programa de Pós-graduação em Artes Visuais da Unicamp, sob orientação do professor Doutor Márcio Donato Périgo. Parte das reflexões deste texto foram apresentadas em um artigo para $\circ 26^{\circ}$ Encontro da Associação Nacional de Pesquisadores em Artes Plásticas e publicada em anal. Disponível em: $<$ http://anpap.org.br/anais/2017/ PDF/PA/26encontro_ DULIANEL_Andr\%C3\%A9ia_Cristina. pdf>. Acesso em 27.out.2018.

2

Andréia Dulianel é artista visual, professora universitária e pesquisadora. Reside em Jundiaí (São Paulo) e trabalha em Campinas (São Paulo). É Bacharel e Licenciada em Artes Plásticas pela Universidade

Estadual de Campinas (2005) e Mestre em Artes (2010) pela mesma instituição. Atualmente é professora

da Faculdade de Artes Visuais da Pontifícia Universidade Católica de Campinas (PUC-Campinas) e doutoranda do Programa de Pós-graduação em Artes Visuais da UNICAMP. Desenvolve pesquisa poética em arte contemporânea, com desenho, diários de desenho,

livros de artista e pintura. Seus trabalhos artísticos estão disponíveis no site https://www.andreiadulianel. 
Meu processo de criação parte do desejo de expressão através da linguagem do desenho, meio mais que propício para o registro de lampejos, impulsos e conflitos, numa relação estreita entre arte e vida. Manifestações intimistas, referentes à nossa condição enquanto seres humanos especialmente nas questões relacionadas ao erotismo, à fragmentação, à fragilidade do ser e à efemeridade da vida - são expressas especialmente através do elemento linha, explorado tanto no espaço bidimensional do papel, quanto no espaço real. A ação de desenhar possibilita uma proximidade com o experimental, com o deixar-se guiar pelo processo, numa busca por movimento visual e transformação constante (relacionada a questões como a provisoriedade e a efemeridade), afinal, enquanto linguagem própria, o desenho indica sempre um porvir. "Tal como o fluxo contínuo do rio de Heráclito, nunca se desenha o mesmo desenho, nunca o traço da linha será igual. Em permanente mutação, a natureza do desenho é sempre a mesma e sempre outra" (DERDYK, 2007, p.17).

Uma das temáticas exploradas, a representação do corpo nu - a partir da observação do modelo vivo ou de autorretratos - merece destaque: há um fascínio pela sinuosidade do contorno do corpo, transformado em linhas ora suaves, ora tensas. Fico intrigada ao representar as formas dos corpos, dos mais maciços aos mais esguios, do feminino ao masculino, explorando as singularidades de cada configuração, trazendo à tona a sensualidade e erotismo que remetem ao toque e às texturas da carne.

Nessas produções procuro desenhar o que é corpo para mim, numa relação subjetiva e pessoal. Não retrato a pessoa que posa como ela é, mas como a vejo, criando distorções e um certo ocultamento da identidade (os corpos são representados em fragmentos e sem a cabeça, o que causa a minimização do retrato). Além disso, é como se buscasse no corpo do outro o que já havia encontrado no meu, afinal há uma proximidade da representação desses corpos com a minha própria imagem, pois a investigação do corpo humano na minha poética começou com a criação de autorretratos.

O nu interessa pelo ato do despir-se, pelo desvelar da essência do ser humano, pelo fato do outro mostrar-se como é aos meus olhos. Escolho amigos próximos, que muitas vezes nunca posaram, os quais dialogam comigo de forma afetiva e diferenciada. Não quero a pose "profissional" 
do modelo, não busco padrões ou estereótipos de poses - apesar de todos nós termos esses referenciais em nossas memórias - procuro um corpo tímido, tenso, que vai amolecendo conforme estabeleço uma relação de troca através do desenho. A partir dessa experiência da observação busco representar como essa relação de troca com o corpo do outro me afeta, na minha relação com o desejo, a sexualidade e a sensualidade, que é revelada na nudez, pela perda do mistério (figuras 1, 2, 3 e 4). John Berger a respeito do nu afirma:

\begin{abstract}
A nudez do outro age como uma confirmação e provoca um forte sentimento de alívio. Ela é uma mulher como outra qualquer: ou ele é um homem como qualquer outro. Ficamos subjugados pela maravilhosa simplicidade do mecanismo sexual que nos é familiar. (BERGER, 1999, p.61).
\end{abstract}

\title{
O velar e o desvelar do corpo
}

Na série "Apagamentos", realizada em 2014 (figuras 5, 6 e 7) e na série "Desdobramentos" de 2016 (figuras 8, 9, 10, 11 e 12) nota-se uma retomada da representação do corpo de uma forma mais velada e menos explícita, em processos que vão da representação a partir dos desenhos de observação de modelo nu, discutidos anteriormente (figuras 1, 2, 3 e 4), em direção a uma quase abstração. O que mais chama a atenção nestes desenhos é o modo como as imagens são criadas, a partir das ações de desvelar/revelar, ou seja, dar forma e configuração ao corpo, deixando explícitos detalhes da figura humana, como também as ações de velar partes, esconder, por conta do excesso de sobreposições das formas (em relações de transparência), ou até mesmo pela ação do apagar partes do desenho, pois elementos visuais como as linhas, manchas e traços são criados, apagados e refeitos, em um movimento constante de construção e desconstrução da imagem.

É interessante levar em consideração que o termo "velar" vem da ideia de cobrir com véu, como também de proteger, de cuidar, de estar de vigia. Na representação do corpo nu, essa relação torna-se fundamental, pois é através do jogo do tornar explícito, do desvelar o corpo, em contraposição ao ato de encobrir, velar, esconder o corpo, que se dá toda 
a poética. $\bigcirc$ jogo entre o mostrar e o esconder tem uma relação com o desejo do erotismo e o impulso/desejo da criação.

Paul Valéry no livro "Degas, Dança, Desenho" (2003, p.149) estabelece uma interessante relação entre a necessidade de criação e o impulso erótico, quando se questiona: "O que há de mais admirável do que a passagem do arbitrário para o necessário, que é o ato soberano do artista, pressionado por uma necessidade, tão forte e tão insistente quanto a necessidade de fazer amor?". Essa relação da arte com a vida, com a pulsão de vida, com o desejo de continuidade, é algo sutil e espiritual, que vai muito além de uma leitura simplista do erotismo, reduzida apenas ao ato sexual em si.

\section{Materialidade e imaterialidade no desenho}

O embate com os materiais, assim como desenvolvimento de técnicas e procedimentos pessoais de criação, sempre foram pontos importantes dentro de minha poética. Neste processo, o carvão é um dos materiais mais explorados, pois além de instigar um diálogo com a tradição, já que é um material recorrente dentro da prática do desenho, me possibilita, por conta de suas características intrínsecas, o trabalho com o provisório, com a efemeridade, questões do meu interesse, tão exploradas na arte contemporânea.

O carvão é um dos mais antigos materiais de desenho utilizados pelo homem desde a pré-história, instrumento interessante para anotações gráficas, pois permite desde registros mais pesados, com boa carga de pressão, depositando-se camadas grossas na criação de sombras mais densas e bem escuras ou de traços largos e intensos, como também ações minuciosas e mais delicadas, como linhas de contorno bem finas e precisas. Essas variações acontecem conforme a inflexão da mão, em gestos que graduam intensidades e qualidades visuais, dando expressividade ao desenho. Mas, muito mais que uma escolha pela recursividade do material dentro da História da Arte, gosto da possibilidade que este recurso dá de reverter um gesto realizado, dando espaço para o equívoco, o arrependimento, através do apagamento. $O$ carvão possibilita um registro da minha busca incansável pela solução desejada, que se dá nesse processo de dar forma e apagar, de revelar e ocultar. 
Rudel (1980, p.62) afirma que o carvão possibilita ao desenhista inúmeros "arrependimentos" ou "repetições". A ideia do arrependimento me atrai, pois tem uma relação forte com a poética que venho desenvolvendo ao trabalhar com o projeto dos "Apagamentos" (figuras 5, 6 e 7). Porém, trata-se de um material contraditório, afinal, ao mesmo tempo em que anota com certa facilidade as ações do desenhista, é extremamente frágil, no que se refere à conservação, sendo um material de certa forma "rústico" ou "pobre". Com relação a esse material, Rudel afirma:

A fragilidade de conservação do carvão por muito tempo limitou-o a um papel secundário, antes que, graças a um meio de fixação permanente, pudesse ser mais amplamente usado, sobretudo a partir do século XVI. Antes era "repetido" a pena ou reforçado com pedra negra. Mas quando se tornou possível fixá-lo (conforme mais adiante), ele passou a ser por sua vez um meio extraordinário de estudo e de realizações para formas um pouco grandes, nos diversos gêneros que atraíam a pintura desde o século XVI. (RUDEL, 1980, p.61).

William Kentridge, artista sul africano, tem despertado interesse dentro de minha poética, em especial pela necessidade de registro em vídeo das ações em desenho. Em um texto de sua autoria Kentridge traz interessantes conclusões sobre a materialidade do carvão: "Apagar o carvão, uma atividade imperfeita, sempre deixa uma mancha cinza no papel. Então, filmar não só registra as mudanças do desenho como revela também a história dessas mudanças, uma vez que cada apagamento deixa uma trilha do que era". (KENTRIDGE, 2013, p. 294).

Os filmes de animação a carvão, ou desenhos filmados de Kentridge, apontam para um processo de criação que se dá também pela constante transformação e movimento do desenho. $O$ artista opta pelo carvão, pois realiza uma técnica de animação em stop motion, na qual retrabalha constantemente o mesmo desenho em um "ritual obsessivo de adição e subtração, acumulação e apagamento" (TONE, 2013, p.9), gerando efeitos gráficos que me interessam e dialogam com o meu método artístico.

Além disso, o artista aparece em seus vídeos, representando o papel de determinados personagens, ou se apresentando como o próprio artista, 
o que reforça o caráter performático de sua produção. Em "Apagamentos I" (figura 5) de 2014, ação em desenho realizada sobre a parede de um quarto vazio, na minha antiga residência em Campinas, essa característica performática também está presente, pois a ação de desenhar e apagar é o trabalho em si. No vídeo/registro ${ }^{3}$ da ação podemos observar o processo de criação de uma imagem e suas transformações: áreas são constantemente apagadas, novas linhas e formas surgem a partir dos vultos e vestígios das imagens, como um desenho que traz em si as lembranças quase apagadas das camadas anteriores. Quero dar ênfase a esse processo, ao gesto do artista e, neste sentido, a minha figura presente no vídeo/registro, desenhando, traçando, apagando, é parte importante para compreensão do desenho enquanto ação.

Neste caso o processo de construção da imagem, a partir das ações de apagamento, foi levado ao limite, pois o ponto central da poética é o constante ato de criação e apagamento, em gestos sucessivos de traçar, apagar e retraçar um desenho na parede de um quarto vazio, finalizando-a com o apagamento total do que fora realizado. A própria efemeridade do material, do carvão, me sugeriu esse caminho. A escolha desse material frágil, assim como a não fixação posterior do desenho e sim de seu apagamento total, corresponde a uma intenção artística de falar sobre questões da existência que muitas vezes são marcadas por vazios, perdas, desaparecimentos, destruições e, por que não, imaterialidades. $\bigcirc$ apagamento total do desenho realizado leva a uma dor, a uma sensação de perda, mas demonstra a coragem de ir além do produto final do desenho, dando mais atenção para o ato de desenhar em si, ao processo.

Como preencher o vazio de perdas e danos causados pela fragilidade de nossa breve existência na terra? Como superar a dor do vazio das perdas, como apagar esse vazio da perda das entranhas de nossa memória? Neste sentido, pude trabalhar o apagamento de toda a memória trágica de vivências pessoais, numa experiência com desenho catártica.

Em "Apagamentos I" (2014) algumas figuras são recriadas a partir de desenhos realizados anteriormente, feitos de observação do nu ("Sem título" de 2014, figuras 1, 2, 3 e 4) e com alguns elementos de imaginação (pássaros) e memória, num jogo de duplicação das figuras no espaço.

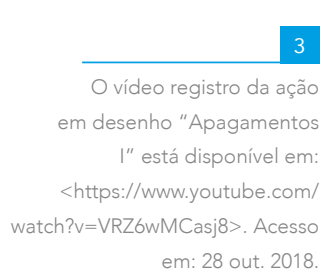

em: 28 out. 2018 
Os desenhos tomam formas reconhecíveis, mas com o processo de apagamento constante, as figuras vão se deformando e abstraindo, criando novas conexões.

O interessante dessa ação é que os traços não foram realizados apenas com a mão agitada, mas com o corpo todo, por conta da ampliação do espaço (formato) do desenho.

Ainda no início da investigação, quando realizava estudos menores, a partir da observação modelo vivo, percebi como a figuras desenhadas tinham uma preocupação com a delimitação da forma, com as linhas de contorno, e anotações de volume através de insinuações de efeitos de luz e sombra (como pode ser observado nas figuras de 1 a 7). Márcio Périgo4, durante as orientações do doutorado, apontou para a possibilidade de pensar as imagens com relação ao que poderia envolver os corpos: como as imagens poderiam ser construídas também através de áreas de manchas pré-estabelecidas, submergindo dessas áreas, ao invés de apenas criar preenchimentos de volume dentro das linhas de contorno da figura. Apontou também a possibilidade do trabalho com outros materiais aliados ao uso do carvão, como técnicas aguadas, explorando tonalidades de cinzas e pretos.

A partir desse desafio, comecei a elaborar qual seria o melhor material para criar esse efeito de mancha no suporte, de onde emergiriam as figuras. Logo pensei na possibilidade de usar o negro de fumo, material que havia explorado há algum tempo e que considerava interessante por ser um pigmento em pó, com materialidade que poderia conversar com a porosidade do carvão. Fiz algumas experiências diluindo o negro de fumo em água e cola de arroz e me encantei como os pretos intensos assim como os semitons obtidos, a partir das variações de cinzas ao diluir o pigmento. Iniciei um desenho em grande escala, "Desdobramentos I" de 2016 (figura 8), onde traço grandes áreas de manchas com pincel, usando o negro de fumo diluído. Das áreas de manchas criadas, observava movimentos visuais e buscava fazer emergir corpos diversos, a partir dos desenhos de modelo vivo realizados anteriormente. O processo era parecido com os trabalhos de séries anteriores, em especial "Apagamentos I e II" (Figuras 5, 6 e 7) onde ia multiplicando fragmentos dos corpos no espaço, repetindo formas que me encantavam e instigavam, criando um outro corpo, feito de múltiplos

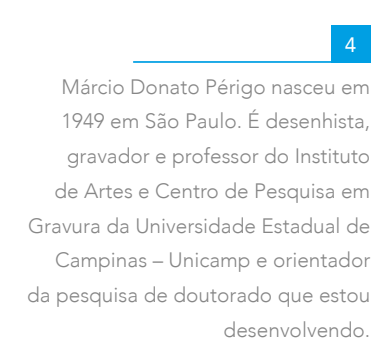


membros e formas. A sobreposição de elementos neste processo foi levada ao limite, tanto que percebemos partes dos corpos representados, mas principalmente a distorção das figuras causada pelo excesso de informação visual sobreposta, resultando numa imagem com grande intensidade e movimento visual. Assim como em "Apagamentos I", percebia o movimento de traçar e apagar traços e áreas do desenho, mas neste caso explorei mais o velamento/ocultamento de partes da figura através da sobreposição das formas, linhas, pontos e manchas, chegando a uma imagem que fez emergir diversas figuras da memória e imaginação, trabalhadas em momentos anteriores da poética, como os pássaros e elementos da paisagem. Das linhas criadas, surgiam outras figuras e formas possíveis, num jogo de mostrar e esconder os corpos em meio a tanta movimentação visual.

Após as primeiras manchas e marcas de pincel com o negro de fumo e os traçados com carvão e pastel seco, senti necessidade de reforçar algumas linhas usando o nanquim, criando movimentos com texturas que remetiam a pelos, cabelos e penas, representando corpos que se fundiam a uma figura animal.

Este primeiro desenho deu origem a outros quatro desenhos grandes (Desdobramentos II,III, IV e V - Figuras 9, 10, 11 e 12), nos quais explorei a confecção de ferramentas de desenho, usando tecidos, pedaços de piaçava e uma vassoura, as quais criavam efeitos visuais interessantes, colocando-me no lugar da experimentação que tanto me agrada e instiga, por trazer efeitos não esperados e incorporados ao acaso, que logo tornamse técnicas pessoais de criação.

No caso do desenho em grande escala, notei que o tamanho do suporte aumentava o tamanho do meu gesto, que por consequência passou a exigir ferramentas mais eficientes: pincéis mais largos, vassouras, tecidos amarrados em bastões, pedaços de carvão mais largos, enfim, uma série de equipamentos que me ajudariam a registrar o gesto do meu corpo no desenho, captando a ação do desenhar com desenvoltura, força e expressão, tão perseguidas no meu percurso. "A ferramenta é uma extensão do corpo do homem criada para ganhar tempo, para ser mais eficiente e para atingir seus desejos além do limite do próprio corpo" (PÉRIGO, 2009, p. 34). Para Heidegger (2012, p.48) "a criação da obra requer, por si mesma, o agir da 
manufactura [das handwerkliche Tun]. Os grandes artistas têm na maior estima o saber fazer de manufactura. São os primeiros a exigir o seu cultivo cuidadoso a partir do pleno domínio." Neste sentido, fica evidente que todo o desenvolvimento das ferramentas, todas as experiências com os materiais novos, revelam uma busca pelo aperfeiçoamento da "manufactura", desenvolvendo um modo genuíno de construção da imagem.

Com o tempo toda essa exploração do movimento e busca do grafismo através das ferramentas ou instrumentos de desenho criados vão se tornando algo natural, como uma extensão do próprio corpo mesmo. Após uma sequência de desenhos criados, o processo de construção da imagem vai ganhando cada vez mais fluidez, deixa-se de pensar tanto nos desafios da matéria e das soluções desejadas, para um caminhar mais espontâneo e intuitivo do gesto do desenho.

Ao lidar com o instrumento no uso, a ocupação se subordina ao ser para (Umzu) constitutivo do respectivo instrumento; quanto menos se ficar na coisa martelo, mais se sabe usá-lo, mais originário se torna o relacionamento com ele e mais desvelado é o modo em que se dá o encontro naquilo que ele é, ou seja, como instrumento. $\bigcirc$ próprio martelar é que descobre o "manuseio" específico do martelo. (HEIDEGGER, 2009, p. 117).

Parafraseando Heidegger (2009), é no próprio desenhar que se descobre o manuseio de cada uma das ferramentas e materiais escolhidos, é no desafio dado por essas materialidades tão específicas, que se vai em busca de uma solução visual mais próxima dos desejos.

Neste processo interessa pensar no como as características intrínsecas dos materiais determinam resultados plásticos, induzem leituras e associações, assim como determinam as ações e reflexões dos artistas. Escolhas materiais estão intimamente relacionadas com vontades artísticas, com necessidades expressivas e, analisar a imagem a partir do meio é importante para entendermos o processo de criação de uma linguagem pessoal que demanda métodos genuínos. Heidegger (2012, p.18) afirma que "o que dá às coisas a sua consistência [das Ständige] e a sua nuclearidade e que origina simultaneamente o tipo do seu afluxo sensível, o colorido, o sonoro, a dureza, o maciço, é a materialidade. Nesta determinação da coisa como matéria está já implicada a forma." 
Outro trabalho que segue nessa mesma linha de pensamento, do desenho enquanto atitude em consonância com as propriedades de um recurso material escolhido, é a ação artística "Evanescências" (figura 13) realizada em espaço público, em junho de 2016, e registrada em vídeo ${ }^{5}$. A ação artística consistiu em realizar um desenho no chão (asfalto), com pincel e água, a partir da observação de elementos da paisagem do espaço público escolhido (um estacionamento que fica no bairro Morada das Vinhas na periferia da cidade de Jundiaí, ao lado de uma rua de acesso bem movimentada). Durante a ação realizei um desenho que foi se apagando em cerca de minutos, por conta da evaporação da água.

(...) a arte site-specific adota estratégias que são agressivamente antivisuais - informativas, textuais, expositivas, didáticas -, ou imateriais como um todo gestos, eventos, performances limitadas pelo tempo. O "trabalho" não quer mais ser um substantivo/objeto, mas um verbo/processo, provocando a acuidade crítica (não somente física) do espectador no que concerne às condições ideológicas dessa experiência. Nesse contexto, a garantia de uma relação específica entre um trabalho de arte e o seu "site" não está baseada na permanência física dessa relação (conforme exigia Serra, por exemplo), mas antes no reconhecimento da sua impermanência móvel, para ser experimentada como uma situação irrepetível e evanescente. (KWON, 2009, pp.170-171)

Toda essa discussão de site-specific desenvolvida por Miwon Kwon (2009) levando em conta o caráter irrepetível e evanescente de alguns trabalhos de arte contemporânea tem uma relação com as ações da série "Apagamentos" de 2014, citadas acima, como também com a segunda ação artística em desenho, "Evanescências" de 2016.

Neste trabalho há um aprofundamento na discussão da materialidade/ imaterialidade da arte, da efemeridade do trabalho: a água dissolve os traços e intenções, a imagem construída e inicialmente definida vai perdendo a sua nitidez, enquanto também me desmancho em suor, por conta dos repetidos movimentos na tentativa de registrar algo com um material tão provisório e evanescente, como numa verdadeira luta contra o tempo e a ação do sol a evolar a água.

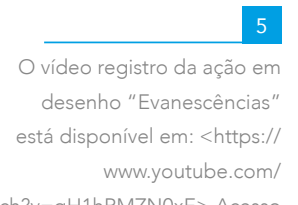


Neste sentido, estabelece-se um diálogo entre o desenho e o espaço real, a realidade tangível do "espaço impuro e ordinário do cotidiano" (KWON, Op.cit.p.167), diferentemente do espaço do cubo branco.

Para Edith Derdyk (2007, p. 19) o sentido originário para a palavra "desenho" tem "recorrências que se impregnam no ato de desenhar presentes na arte contemporânea que apreende o desenho também como atitude, e não somente como 'apenas coisa de lápis e papel'"b.

Uma ideia de desenho alça voos maiores do que ser "apenas coisa de lápis e papel". A essa formulação, já mencionada, Mário de Andrade soma outras afirmações, com propriedade, convergindo para a noção de que "o verdadeiro limite do desenho não implica de forma alguma o limite do papel, nem mesmo pressupondo margens", sugerindo a qualidade expansiva que 0 desenho assume enquanto linguagem extensiva aos pensamentos, aos desejos e às atuações no mundo. (DERDYK, 2007, p.21).

Faço uma interpretação dessa noção de desenho delimitada por Mário de Andrade, dentro de minha poética, como sendo uma arte que é coisa sobre papel, como também sobre outros suportes (parede, chão...). Como uma ação ante o mundo sensível, que vai muito além de uma mera representação de algo observado, para o expressar de um ser/estar no mundo, afinal a nossa presença é "espacial", no tocante ao nosso "ser- nomundo" (HEIDEGGER, 2009), um gesto que revela muito da nossa forma de perceber as coisas e pensar sobre elas, através de experimentações inusitadas, inclusive.

\section{Desenho em campo expandido e desenho como ação}

Muitas das séries de desenho criadas são resultado de uma pesquisa em diálogo com a tradição do desenho, já outros trabalhos exaltam a imaterialidade, a efemeridade de alguns processos: como as intervenções com desenho em espaços expositivos, ações em desenho registradas em vídeo e uso de materiais e suportes inusitados, discutidos anteriormente. Neste eixo a discussão do processo em detrimento do produto final e a evidência dada ao gesto do desenhar ganha importância.

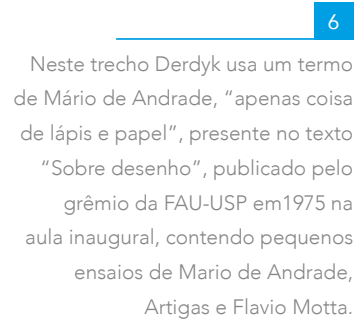

Artigas e Flavio Motta. 
Entretanto, a discussão do espaço do desenho tem tomado cada vez mais corpo dentro da poética, afinal se trabalho com desenho e linhas no espaço bidimensional, estou lidando com um elemento de denota noções de direção, movimento, delimitação, todas relacionadas com as questões espaciais que se iniciam em nossa vivência de mundo. Fayga Ostrower no capítulo "Espaço e expressão" do livro "Universos da Arte" (2004) fala sobre a ligação da noção de espaço com a nossa vivência, uma experiência que é ao mesmo tempo "pessoal" e "universal", pois faz parte da nossa forma de vivenciar e conhecer o mundo através do corpo.

Experiência quase primeva, na necessária recorrência e constante atualidade, a percepção do espaço não é restrita a individualidades e nem mesmo a certas culturas. Pela sensação de estarmos contidos num espaço e de o contermos dentro de nós, de o ocuparmos e transpormos, de nele nos desequilibrarmos e reequilibramos para viver, o espaço é vivência básica para todos os seres humanos. Além disso, o espaço constitui o único mediador que temos entre nossa experiência subjetiva e a conscientização dessa experiência. Tudo aqui que nos afeta em termos de vida precisa assumir uma imagem espacial para poder chegar ao nosso consciente. E do mesmo modo, tudo o que queremos comunicar sobre valores da vida traduzimos em imagens de espaço. Ao dizermos, por exemplo, que algo nos toca de modo profundo ou apenas superficial, usamos intuitivamente imagens de espaço. Quando falamos das qualidades em um indivíduo (um ser in-divisível), como sendo aberto ao mundo ou fechado, expansivo ou introvertido, desligado, envolvente, atraente, repulsivo, distante, próximo, usamos sempre imagens de espaço. (OSTROWER, 2004, p.13, grifo do autor).

As conjecturas da autora são importantes na discussão de minha produção, pois encaro o desenho como uma das linguagens mais interessantes para expressar as minhas vivências pessoais. Faço isso através das marcas visuais deixadas, dos movimentos das linhas e do direcionamento das mesmas no espaço, na forma como organizo os elementos no suporte, independente de qual seja, deixando evidente como estão imbricadas as imagens de espaço com o modo como me relaciono com o mundo, com a vida. 
Paul Valéry (1871 - 1945) no livro "Degas Dança Desenho" (2003) traz, através de termos poéticos, uma interessante descrição do trabalho e lugar de criação do artista, ainda relacionada a uma visão modernista.

Ocorre-me por vezes de achar que o trabalho do artista é um tipo muito antigo de trabalho; o próprio artista é uma sobrevivência, um operário ou artesão de uma espécie em vias de extinção, que fabrica fechado em seu quarto, usa procedimentos muito pessoais e muito empíricos, vive na desordem e na intimidade de suas ferramentas, vê o que quer e não o que o cerca (VALERY, 2003, p.41)

As belas palavras do poeta acima citado, fazem sentido no meu processo de criação, pois minha produção ainda tem um caráter muito intimista e introspectivo. Mas, por outro lado, pode-se notar que o trabalho tem ganhado um outro caráter nesses últimos anos de investigação e a ideia do artista que produz fechado em seu quarto, acaba sendo de certa forma ampliada, quando decido usar o espaço do quarto, as paredes, como suporte para traçar minhas ideias confusas e para apagar tudo logo em seguida.

A necessidade de sair desse lugar de isolamento, em oposição à ideia do artista como "gênio solitário" me levou a fazer uma intervenção em desenho no espaço do Museu Histórico e Cultural de Jundiaí- Solar do Barão, "Apagamentos II" em 2015 (figuras 6 e 7), no qual realizei o mesmo processo de criação, de traçar, apagar um desenho diretamente no painel do museu. Neste trabalho exponho uma etapa do desenho que têm existência efêmera e é apagado ao fim da exposição.

Já em "Evanescências" de 2016 (figura 13) podemos notar a conquista do espaço aberto (público), questão que o próprio trabalho já estava indicando, num processo gradativo: dos desenhos sobre papel para o espaço do quarto, do espaço do quarto para o espaço do museu e, finalmente, do espaço do cubo branco para o mundo, num processo de busca pela visibilidade, mas especialmente pelo contato mais estreito com o campo do outro.

Francis Alÿs foi uma referência importante na concepção dessa ação, em especial o trabalho "Paradoxes of Praxis 1" (1997) no qual o artista empurra um enorme bloco de gelo pelas ruas da Cidade do México. A atitude de arrastar o gelo até o seu desaparecimento, deixando rastros de água que 
rapidamente sumiam, me influenciou na elaboração da ideia de intervenção efêmera no espaço público, dando importância para a experiência artística em si. Outra artista que também trabalha com a questão do efêmero é a mineira Cinthia Marcelle. Gosto particularmente da instalação "Sobre este mesmo mundo" de 2009, uma grande lousa com os vestígios do pó do giz branco acumulado na canaleta, resquícios das ações de apagamento. Esta última obra pude ver pessoalmente na $29^{a}$ Bienal de São Paulo e causou grande impacto. Além da brasileira, vale destacar o britânico Andy Goldsworthy que trabalha com as deambulações pelo ambiente natural, criando esculturas e intervenções efêmeras no espaço. Todo o relato do seu processo no documentário "Rivers and Tides" de 2011 é inspirador.

O espaço público escolhido para a ação "Evanescências" se deu por ser um dos lugares de passagem diária no trajeto casa/trabalho, o qual observei com mais cuidado ao pensar a proposta de ação artística. Ao passar pela rua, procurei um local no qual pudesse realizar a minha ação e que tivesse certa visibilidade. Observei em diferentes momentos do dia e fiz a escolha pelo horário do fim da tarde, o que deu uma luz interessante para o vídeo (registro), criando sombras e outras projeções no espaço que me interessaram esteticamente.

Significa, em primeiro lugar, que tudo o que vem a público pode ser visto e ouvido por todos e tem a maior divulgação possível. Para nós, a aparência - aquilo que é visto e ouvido pelos outros e por nós mesmos - constitui a realidade. Em comparação com a realidade que decorre do fato de que algo é visto e escutado, até mesmo as maiores forças da vida íntima - as paixões do coração, os pensamentos da mente, os deleites dos sentidos - vivem uma espécie de existência incerta e obscura, a não ser que, e até que, sejam transformados, desprivatizadas e desindividualizadas, por assim dizer, de modo a se tornarem adequadas à aparição pública. A mais comum dessas transformações ocorre na narração de histórias e, de modo geral, na transposição artística de experiências individuais. Mas não precisamos da forma do artista para testemunhar essa transfiguração. Toda vez que falamos de coisas que só podem ser experimentadas na privacidade ou na intimidade, trazemo-las para uma esfera na qual assumirão uma espécie de realidade que, a despeito de 
sua intensidade, elas jamais poderiam ter tido antes. A presença dos outros que vêem o que vemos e ouvem o que ouvimos, garante-nos a realidade do mundo e de nós mesmos; e, embora a intimidade de uma vida privada plenamente desenvolvida, tal como jamais se conheceu antes do surgimento da era moderna e do concomitante declínio da esfera pública, sempre intensifica e enriquece grandemente toda a escala de emoções subjetivas e sentimentos privados, esta intensificação sempre ocorre às custas da garantia da realidade do mundo e dos homens. (ARENDT, 2007, pp 59 e 60).

As pessoas que transitaram pela rua puderam testemunhar uma experiência de transformação momentânea do espaço público, um contato com minha ação criadora, que foi para além das paredes de um museu, para as ruas. Vale ressaltar que durante a ação permaneci o tempo todo submersa e concentrada na ação do traçar, retraçar e lutar contra o processo de apagamento da imagem, não tendo um contato mais íntimo com o público. Este processo foi enriquecedor no que diz respeito ao meu trabalho, pois pude vislumbrar novas possibilidades de criação, o que gerou uma reflexão mais aprofundada sobre minha arte no mundo, relacionando o desenho com ações do cotidiano, pois ao observar posteriormente o vídeo/registro, em especial os enquadramentos feitos a distância, percebi que o ato de desenhar aproximou-se de atos corriqueiros do cotidiano, como o ato de lavar o chão, por exemplo. Neste sentido, fiquei pensando se as pessoas que passaram pela rua perceberam que eu estava desenhando ou, por conta de carregar um balde com água e jogála no chão, viram apenas uma pessoa lavando o asfalto.

Para finalizar, vale a pena relatar a última ação/performance em desenho realizada em 2018, intitulada "Volubilidade"7 (a ação foi realizada no dia 15 de setembro de 2018, na mostra coletiva "Urubu Rei" organizada em conjunto com o "Atelier Contágio" e o "Goma Arte e Cultura"8). Nesta ação/performance fiz um trabalho que trouxe elementos das duas outras ações: o trabalho com a imaterialidade do carvão e da água, continuando com a pesquisa dos apagamentos e da efemeridade.

Por buscar uma relação da minha subjetividade com as questões relacionadas ao ambiente e paisagem, pensei em realizar um desenho

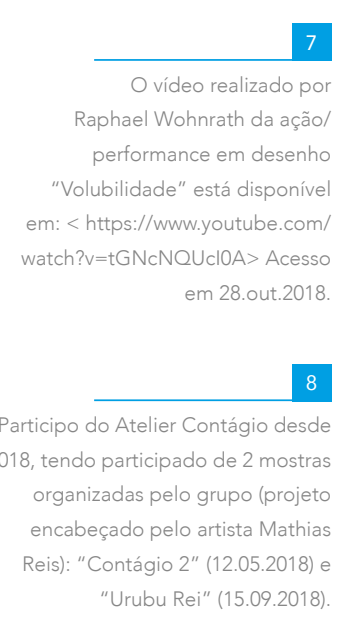


que envolvesse os quatro elementos, trabalhando com a materialidade do pó do carvão (resultante da queima e combustão da madeira em contato com o fogo), a água, a terra (representada pela argila) e o ar. A ação aconteceu em algumas etapas: num primeiro momento delimitei uma área a ser trabalhada, pintando um quadrado no chão com argila branca, um lugar fechado para a minha ação performática, o qual remetia ao suporte do papel. Esse espaço delimitado representa para mim um espaço de circunscrição e introspecção, o dentro, o subjetivo, a proteção.

Após alguns minutos, quando o chão estava seco, iniciei a ação de jogar pó de carvão sobre o chão, no centro do quadrado delimitado (a ideia era iniciar o desenho a partir do centro em movimentos crescentes e circulares). O pó logo se espalhou pelo chão e pelo ar e pude observar encantada o movimento do ar, a criar desenhos com a névoa do carvão?. Outro acontecimento interessante durante a performance, que não estava no meu plano inicial, foi o fato do pó preto ter se espalhado ao redor do meu pé (o qual criou uma espécie de máscara) e ter formado o desenho de sua silhueta sobre o chão de argila. No momento aquilo me encantou, pois me lembrei dos desenhos nas paredes das cavernas primitivas, feitas com a pulverização da tinta contornando a forma das mãos. Sendo assim, segui o fluxo desse acontecimento e comecei a jogar pó de carvão sobre as extremidades do meu corpo, criando um desenho com as silhuetas iluminadas de meus pés e mãos sobre o intenso fundo preto de carvão (figura 14).

Logo em seguida fui depositando carreiras de carvão pelo chão (ação já planejada anteriormente), criando linhas e contornos de formas que rementiam a desenhos meus anteriores, como partes de corpos, especialmente pernas, seios e barriga (figura 15). Depois do desenho formado, comecei a espalhar o carvão de um lado para o outro, usando as mãos, trinchas pressas a um cabo extensor e os pés, apagando partes do desenho realizado e criando novas formas, a partir da retirada da matéria. Redesenhei mais algumas partes, criando novas formas, agora mais abstraídas, por conta da sobreposição das ações de desenhar e apagar.

Finalmente, parti para o apagamento total do desenho: primeiramente varri todo o pó do carvão e recolhi os vestígios do desenho com uma pá. Em seguida comecei a lançar água sobre o chão (usando um balde) e a limpar o chão. Neste momento manchas formaram-se e o carvão misturou-se à

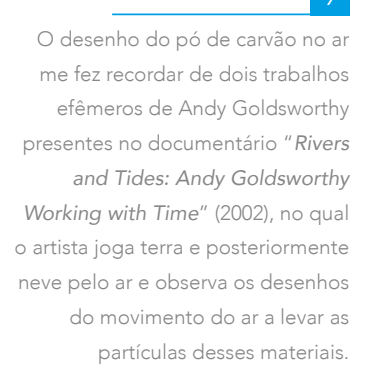


argila branca, criando um belo efeito visual. Aos poucos fui esfregando o chão com a vassoura e o rodo, até que não sobrasse mais nenhum vestígio da ação do desenhar (figura 16). Nesta última parte da ação/performance o desenhar (assim como havia relatado na ação "Evanescências" de 2016) mistura-se com ações cotidianas corriqueiras, como o varrer, o recolher a sujeira com a pá, o lavar o chão, o arrastar água com o rodo, enfim, ações não relacionadas com o que tradicionalmente poderia se chamar de ação do desenhar, mas que para mim tornou-se um desenhar.

O público presente pode assistir a todas as ações realizadas, do pintar o chão, ao traçar o desenho, do varrer ao lavar o chão, ações realizadas com a mesma importância. Neste sentido, o desenhar perde um suposto "status" de superioridade, para se integrar às ações corriqueiras. Foi interessante acompanhar a reação das pessoas, especialmente de crianças que estavam no local e tentavam interagir comigo, perguntando porque estava fazendo aquilo e como conseguia construir o desenho. No momento da criação fiquei submersa e não interagi com ninguém, não respondendo ao questionamento das crianças, as quais foram insistentes e chegaram até e me cutucar (literalmente). Ao terminar a performance, os questionamentos das crianças me levaram a repensar as minhas ações: não seria interessante buscar uma maior participação do outro? Por mais que eu estivesse realizando uma ação em espaço aberto, não tão fechado como o espaço do meu atelier, ainda assim criei toda uma situação de reclusão e isolamento. As crianças me provocavam o tempo todo, como que a me acordar do transe e do isolamento da criação, me chamando para um contato mais estreito com a realidade, "com os homens" e "com o mundo", afinal, como conclui Hannah Arendt (2007), na última citação realizada, quando o privado ganha a esfera pública, a "presença do outro" pode nos garantir "a realidade do mundo e de nós mesmos", fator que pode intensificar e enriquecer "grandemente toda a escala de emoções subjetivas e sentimentos privados". Esta é uma questão que me intriga atualmente, deixando uma reticência no meu processo de criação, indicando um porvir.

\section{Referências Bibliográficas}

ARENDT, H. A Condição humana. Rio de Janeiro: Forense Universitária, 2007.

BERGER, John. Modos de ver. Rio de Janeiro: Rocco, 1999. 
DERDYK, Edith. (Org.) Disegno. Desenho. Desígnio. São Paulo: Editora Senac, 2007.

ELUF, Lygia. Lygia Eluf (Artistas da Usp:13). São Paulo: Edusp, 2004.

HEIDEGGER. Martin. A origem da obra de arte. Lisboa: Edições 70, 2012.

HEIDEGGER. Martin. Ser e tempo. Petrópolis: Vozes, 2009. GENET, Jean. O ateliê de Giacometti. São Paulo: $\quad$ Cosac \& Naify, 2000.

KENTRIDGE, William. "Fortuna": nem programa, nem acaso na realização de imagens. In: TONE, Lilian (org.). William Kentridge: Fortuna. Catálogo da exposição William Kentridge: Fortuna.São Paulo: Pinacoteca do estado de São Paulo, 2013.

KWON, M. Um lugar após o outro: anotações sobre site-specificity. Arte \& Ensaios. Rio de Janeiro: Programa de Pós-Graduação em Artes Visuais da EBA-UFRJ, $n^{\circ} 17$, pp. 167-187,2009.

LANCRI, Jean. Modestas proposições sobre as condições de uma pesquisa em Artes Plásticas na Universidade. In: BRITES Blanca, TESSLER, Elida.

(Org.). O meio como ponto zero: Metodologia da Pesquisa em

Artes Plásticas. Porto Alegre: Editora da UFRG, 2002. p. 16-33.

OSTROWER, Fayga. Acasos e criação artística. Rio de Janeiro: Campus,1999.

Universos da Arte. Rio de Janeiro: Elsevier, 2004.

PÉRIGO, Márcio. Caos aparente. Campinas - SP. Tese de Doutorado. Orientadora: Lygia Arcuri Eluf. Instituto de Artes da Universidade Estadual de Campinas, 2009.

RUDEL, Jean. A técnica do desenho. Rio de Janeiro: Zahar, 1980.

TONE, Lilian (org.). William Kentridge: Fortuna. Catálogo da exposição William Kentridge: Fortuna.São Paulo: Pinacoteca do estado de São Paulo, 2013.

VALÉRY, Paul. Degas Dança Desenho. São Paulo: Cosac \& Naify Edições, 2003 

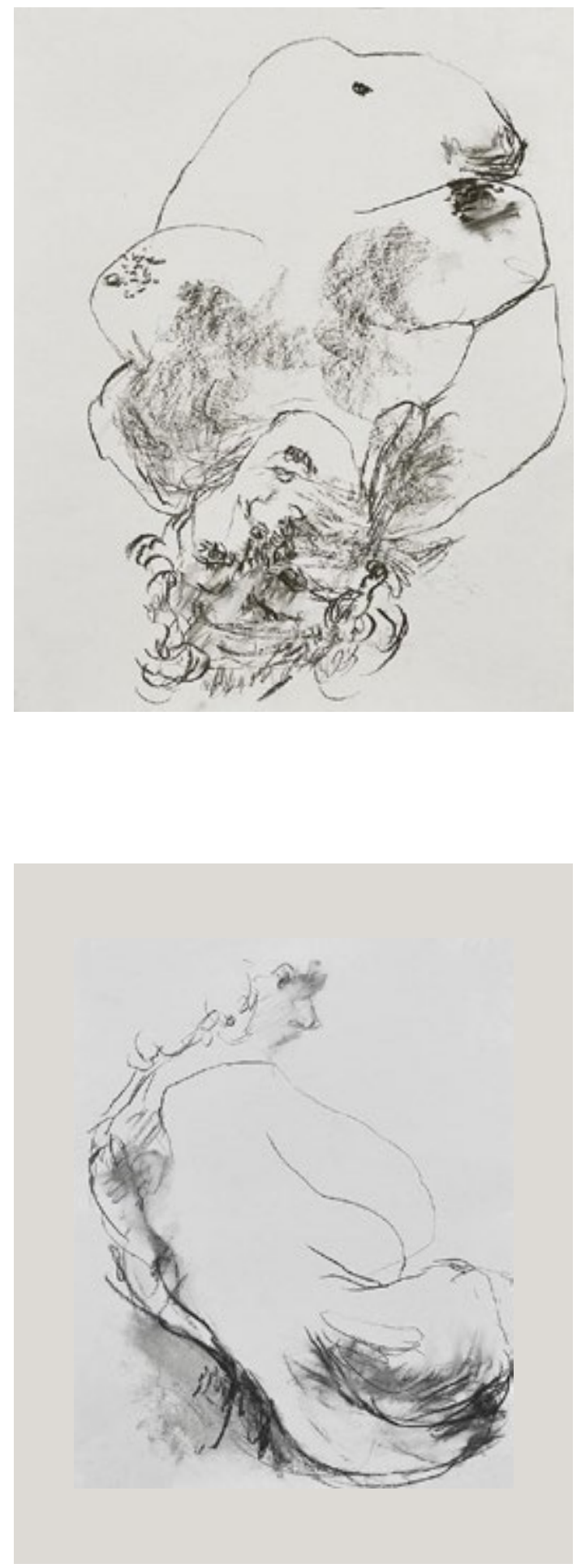

Figura 1. Andréia Dulianel

Sem título (Desenhos de modelo

vivo), 2014.

Carvão sobre papel

$42 \times 52,5 \mathrm{~cm}$.

Fonte: Elaborada pela autora
Figura 2. Andréia Dulianel

Sem título (Desenhos de modelo vivo), 2014

Carvão sobre papel $42 \times 52,5 \mathrm{~cm}$.

Fonte: Elaborada pela autora 

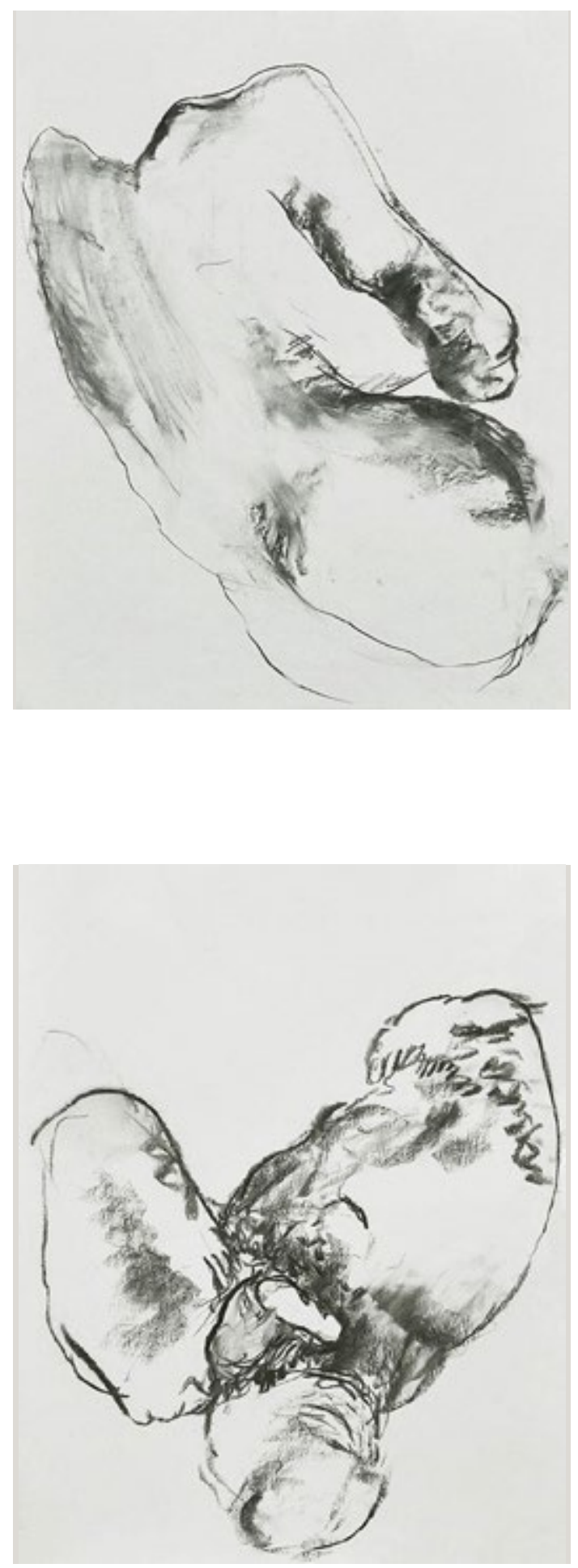

Figura 3. Andréia Dulianel

Sem título (Desenhos de modelo vivo), 2014

Carvão sobre papel $42 \times 52,5 \mathrm{~cm}$.

Fonte: Elaborada pela autora

Figura 4. Andréia Dulianel

Sem título (Desenhos de modelo vivo), 2014

Carvão sobre papel $42 \times 59 \mathrm{~cm}$

Fonte: Elaborada pela autora 

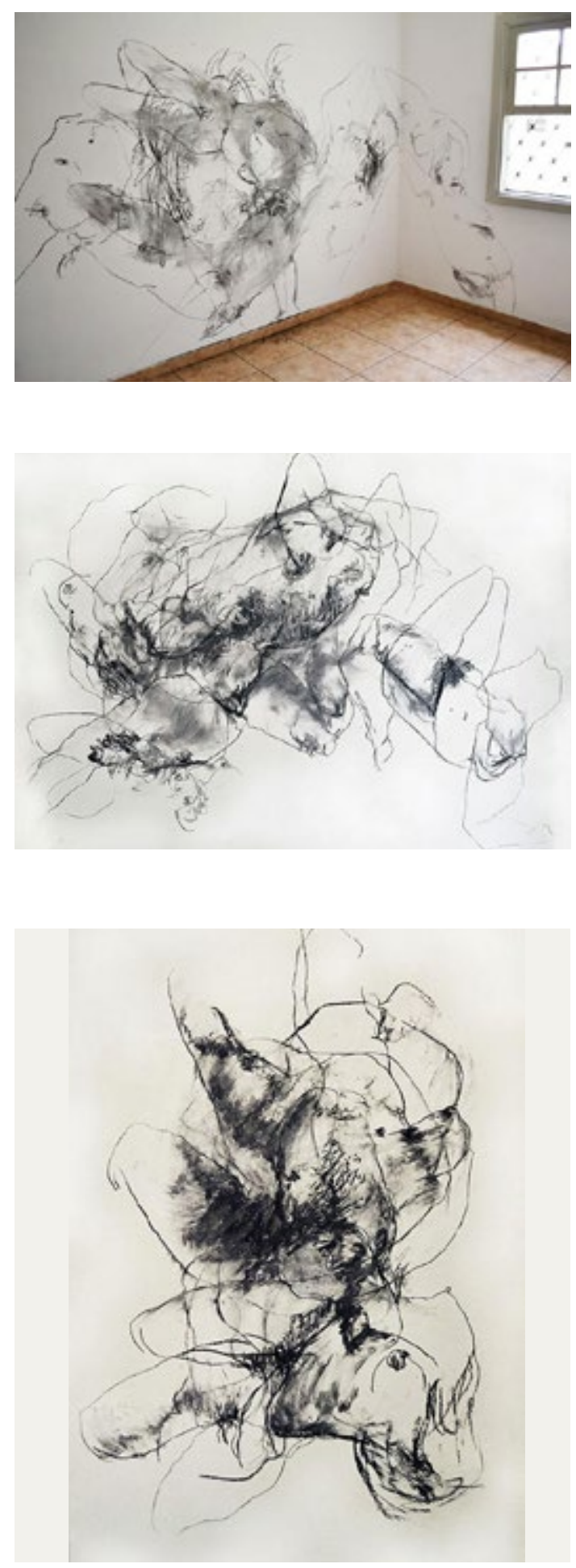

Figura 6. Andréia Dulianel

"Apagamentos II", 2015

Carvão sobre parede. Intervenção em desenho no painel no Museu Solar do Barão, Jundiaí-SP, realizada em julho de 2015

$1,83 \mathrm{~m} \times 2,75 \mathrm{~m}$

Fonte: Elaborada pela autora

Figura 7. Andréia Dulianel

"Apagamentos II", 2015

Carvão sobre parede.

Intervenção em desenho no painel no Museu Solar do Barão, Jundiaí-SP, realizada em julho de 2015 1,37 $\mathrm{m} \times 1,83 \mathrm{~m}$

Fonte: Elaborada pela autora 

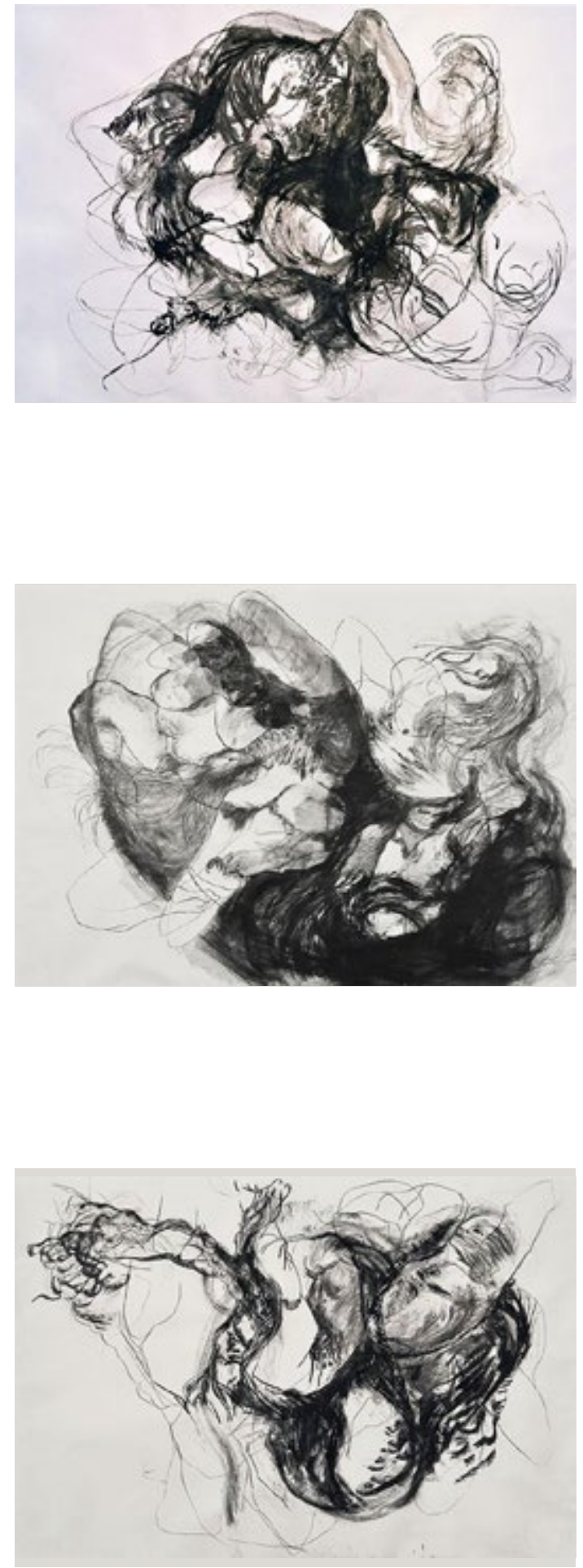

Figura 8. Andréia Dulianel

"Desdobramentos I", 2016

Carvão, pastel seco, negro de fumo e nanquim sobre papel

$2,20 \mathrm{~m} \times 1,50 \mathrm{~m}$

Fonte: Elaborada pela autora

Figura 9. Andréia Dulianel

"Desdobramentos II", 2016

Carvão, pastel seco, negro de fumo e nanquim sobre papel

$2,20 \mathrm{~m} \times 1,50 \mathrm{~m}$

Fonte: Elaborada pela autora

Figura 10. Andréia Dulianel

"Desdobramentos III", 2016

Carvão, pastel seco, negro de fumo e nanquim sobre papel

$2,20 \mathrm{~m} \times 1,50 \mathrm{~m}$

Fonte: Elaborada pela autora 

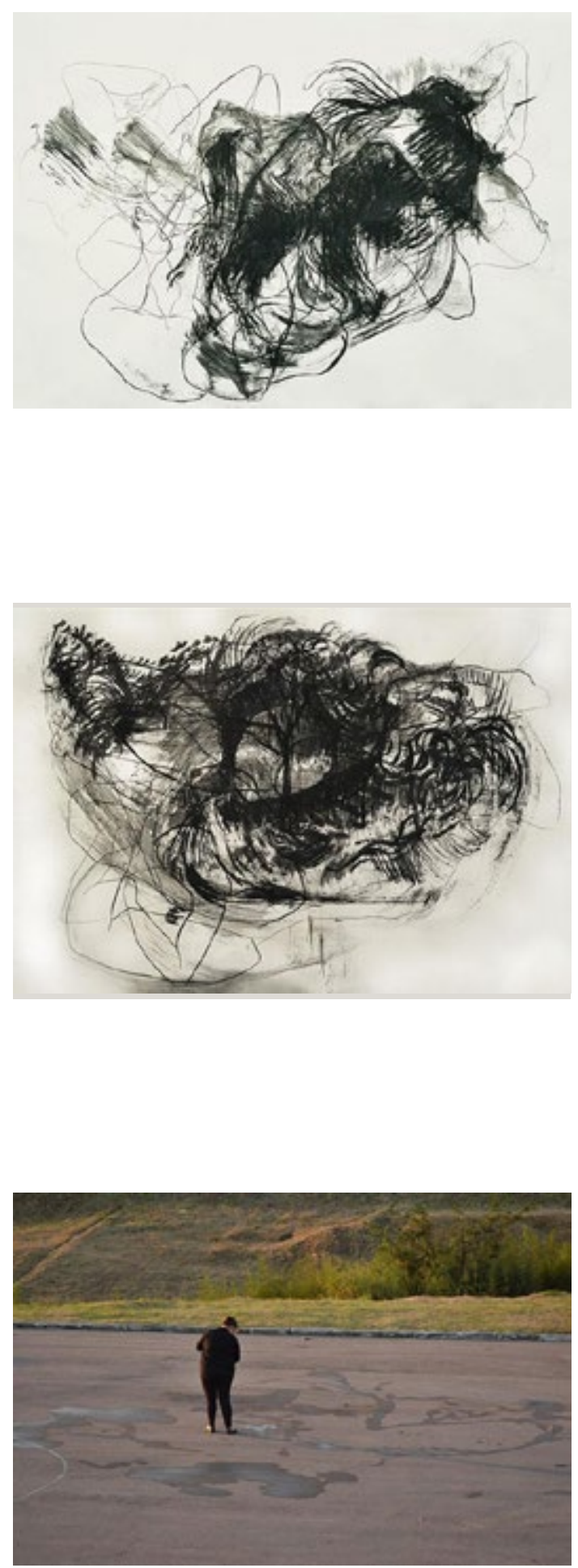

Figura 11. Andréia Dulianel "Desdobramentos IV", 2016 Carvão, pastel seco, negro de fumo e nanquim sobre papel $2,20 \mathrm{~m} \times 1,50 \mathrm{~m}$

Fonte: Elaborada pela autora

Figura 12. Andréia Dulianel "Desdobramentos V", 2016 Carvão, pastel seco, negro de fumo e nanquim sobre papel $2,20 \mathrm{~m} \times 1,50 \mathrm{~m}$

Fonte: Elaborada pela autora

Figura 13. Andréia Dulianel

"Evanescências", 2016

Água sobre asfalto

Fonte: Gabriel Dulianel 


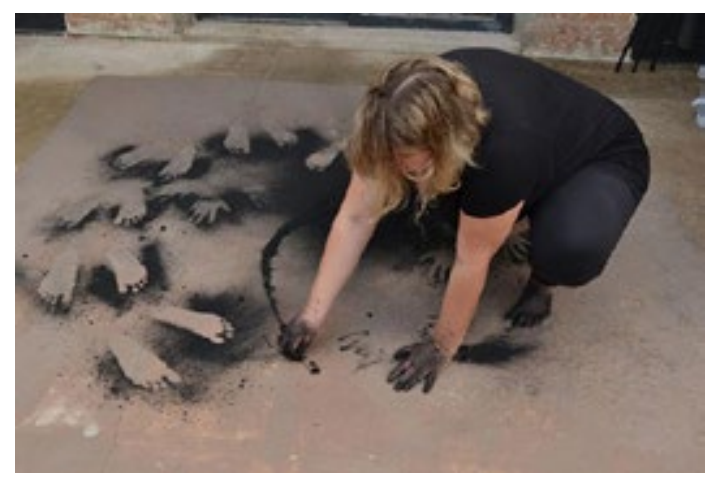

Figura 14. Andréia Dulianel

"Volubilidade", 2018

Argila branca, carvão e água sobre chão

Fonte: Gabriel Dulianel

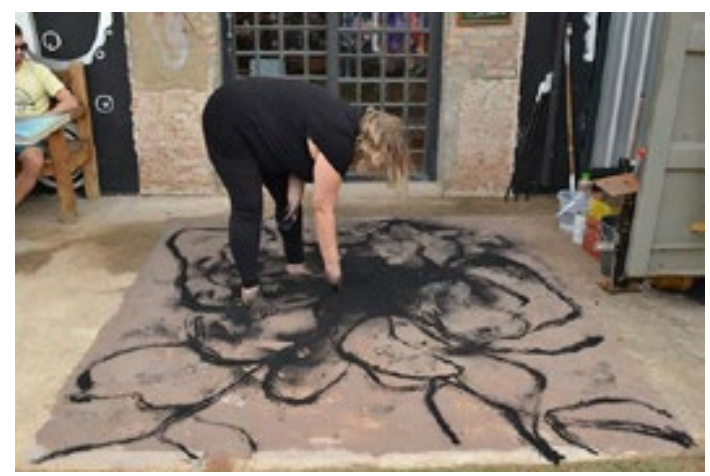

Figura 15. Andréia Dulianel

"Volubilidade", 2018

Argila branca, carvão e água sobre chão

Fonte: Gabriel Dulianel

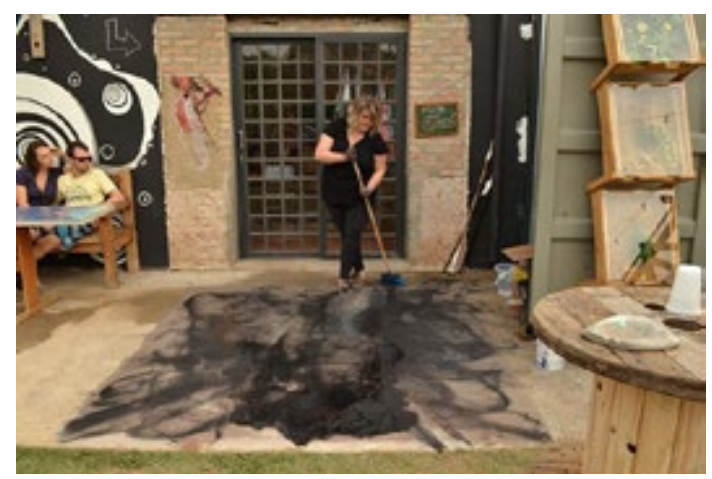

Figura 16. Andréia Dulianel

"Volubilidade", 2018

Argila branca, carvão e água sobre chão

Fonte: Gabriel Dulianel 